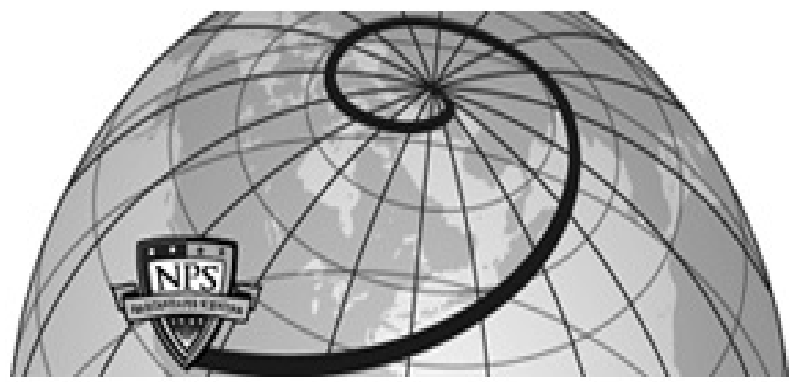

Calhoun: The NPS Institutional Archive DSpace Repository

\title{
Dynamic Model of Firm Valuation: A New Methodology and its Empirical Validity
}

Lazzati, Natalia; Menichini, Amilcar A.

https://hdl.handle.net/10945/44907

This publication is a work of the U.S. Government as defined in Title 17, United States Code, Section 101. Copyright protection is not available for this work in the United States.

Downloaded from NPS Archive: Calhoun

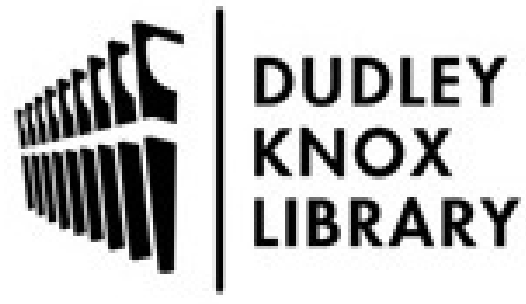

http://www.nps.edu/library
Calhoun is the Naval Postgraduate School's public access digital repository for research materials and institutional publications created by the NPS community. Calhoun is named for Professor of Mathematics Guy K. Calhoun, NPS's first appointed -- and published -- scholarly author.

Dudley Knox Library / Naval Postgraduate School 411 Dyer Road / 1 University Circle Monterey, California USA 93943 


\title{
Dynamic Model of Firm Valuation:
}

\section{A New Methodology and its Empirical Validity}

\author{
Natalia Lazzati and Amilcar A. Menichini*
}

November 14, 2014

\begin{abstract}
This study derives a dynamic version of the dividend discount model and assesses its empirical validity. The valuation method we propose can be easily implemented and uses widely available financial data. We find that our model produces equity value estimates that are, on average, very close to market prices, and explains a large proportion of the variation observed in contemporaneous share prices. In addition, the model we offer is a good predictor of longterm cross-sectional stock returns. For instance, a simple buy-and-hold strategy consistently earns around $22 \%, 37 \%$, and $49 \%$ returns after one, two, and three years of portfolio formation.

JEL classification: G31, G32

Keywords: Firm Valuation; Dividend Discount Model; Gordon Growth Model; Dynamic Programming
\end{abstract}

\footnotetext{
${ }^{*}$ Natalia Lazzati is from the Department of Economics, University of Michigan, Ann Arbor, MI 48109 (e-mail: nlazzati@umich.edu). Amilcar A. Menichini is from the Graduate School of Business and Public Policy, Naval Postgraduate School, Monterey, CA 93943 (e-mail: aamenich@nps.edu).
} 


\section{Introduction}

We derive a dynamic model of the firm in closed-form that can be used for actual firm valuation. To test its empirical validity, we price firms currently in the S\&P 100 Index and evaluate the results from different perspectives. First, we find that the model produces consistent forecasts of stock prices. That is, we compute the ratio of the actual market prices to the values predicted by our model and its median (mean) value turns out to be 1.01 (1.12). Second, we investigate the proportion of the variation in current stock prices that our model estimates can explain. To this end, we regress the market value of equity on the value estimated by the model and find that it can explain a large fraction of that variability (around 75\%). Finally, we analyze whether the model can be used to predict future stock returns in the cross-section of firms and take economic advantage of the differences between estimated and observed values. We find that simple buy-and-hold strategies yield substantial positive returns during the three years following portfolio formation. For instance, our results show that those strategies earn, on average, around $22 \%, 37 \%$, and $49 \%$ returns after 12, 24, and 36 months, respectively, of portfolio construction. Overall, these results suggest our model is a promising pricing tool.

The dynamic model we derive in this article links two different strands of literature, namely, dynamic programming models of the firm and firm valuation models. The former have been used extensively in corporate finance to explain firm behavior. ${ }^{1}$ Our model differs from this literature in three fundamental ways, making it particularly useful for asset pricing. First, the model is based on the separation principle, which states that managers maximize shareholders' wealth by undertaking the investments that maximize firm value, independently of equity-holders' personal preferences. Thus, our approach does not require any assumption about shareholders' utility functions, as long as we discount future cash flows with an appropriately risk-adjusted discount rate. $^{2}$ Dixit and Pindyck (1994) suggest the possibility of using dynamic programming techniques for firm valuation. We believe our paper is one of the first attempts in this direction. Second, we introduce long-run growth, which could be interpreted as the possibility of the firm

\footnotetext{
${ }^{1}$ Strebulaev and Whited (2012) provide a comprehensive review of this growing literature.

${ }^{2}$ See, for example, Copeland, Weston, and Shastri (2005) for a more complete discussion of the separation principle.
} 
to take advantage of new, profitable investments in the future. As documented by Lazzati and Menichini (2014a), long-run growth can account for more than $30 \%$ of the value of the firm, and it is of particular importance for certain industries, such as manufacturers of chemical products and industrial machinery, providers of communication services, etc (Jorgenson and Stiroh (2000)). Third, we solve the model in closed-form, which substantially simplifies its practical implementation. ${ }^{3}$

Our paper is also related to the literature on firm valuation models. Generally accepted valuation models include the dividend discount model (DDM), the discounted cash flow model (DCFM), and the residual income model (RIM). ${ }^{4}$ We contribute to this literature by deriving a dynamic version of the DDM in closed-form. Our model constitutes an improvement of those models in the sense that it yields the stock price as an analytic function of the economic fundamentals of the firm (i.e., volatility and mean-reversion of profits, depreciation rate, elasticity of capital, etc.) In other words, we provide explicit microeconomic foundations for those models using dynamic programming techniques in the context of share price maximization. This closedform solution leads, in turn, to a new approach to firm valuation that involves only two steps. First, model parameters must be calibrated or estimated, for which historical financial statements can be employed. Second, using only contemporaneous and observable information, such as the current values of book equity and gross profits, our model estimates the stock price by solving systematically for the infinite sequence of expected future dividends.

The valuation approach we propose simultaneously solves two issues that often affect the practical implementation of the aforementioned standard valuation methods. First, those methods typically involve forecasting future values for a finite number of years. Given the natural

\footnotetext{
${ }^{3}$ As it is common with other valuation models (e.g., the Black-Scholes formula), we do not introduce adjustment or transaction costs to our model.

${ }^{4}$ The DDM is attributed to Williams (1938), while the DCFM is described in detail by Copeland, Weston, and Shastri (2005), and Koller, Goedhart, and Wessels (2010), among others. The RIM was originally introduced by Preinreich (1938) and Edwards and Bell (1961), and more recently extended by Ohlson (1991, 1995). While theoretically equivalent, the three valuation models differ with respect to the information used in their practical implementation. The DDM uses the future stream of expected dividend payments to shareholders. The DCFM is based on some measure of future cash flows, such as free cash flows. Finally, the RIM uses accounting data (e.g., current and future book value of equity and earnings).
} 
uncertainty involved in future predictions, these projections become increasingly more difficult to make the farther they are in the future. Second, they also require predicting a terminal or continuation value, which represents the value of the firm at the end of the forecast horizon. This terminal value often represents a large part of the current value of the firm and is sometimes based on ad hoc calculations. The method we propose incorporates future uncertainty into the decision process of the firm in a systematic way, which is then reflected in the resulting stock price. In addition, our model does not require forecasting any future value (including an arbitrary terminal value). A further feature of our valuation approach is that it can be easily converted into an n-stage dividend discount model by properly adjusting the future growth rates.

Several papers have studied the empirical performance of the standard pricing models. For instance, Kaplan and Ruback (1995) study the ability of the DCFM to explain the observed market values of 51 highly leveraged transactions. They find that the model produces estimates that are, on average, within $10 \%$ of the market prices. Bernard (1995) compares the ability of the DDM and RIM to explain the observed variation in stock prices. He finds that the RIM explains $68 \%$ of the variability in market values and outperforms the DDM, which can only explain $29 \%$ of such variation. Frankel and Lee (1998) test the RIM empirically and find that the model estimates are highly correlated with current stock prices. They also find that the model helps predict long-term cross-sectional stock returns relatively well. Copeland, Weston, and Shastri (2005) test the validity of the DCFM using a sample of 65 firms and find that the model produces value estimates that are quite close to market values. We find that our dynamic valuation model yields equity value estimates that are, on average, very close to market values. Specifically, the median distance between estimated values and market prices is only 1\%. In addition, our value estimates explain around $75 \%$ of the variation in current share prices. Finally, our model forecasts future cross-sectional stock returns very well, producing substantially positive average buy-andhold returns that are higher than those reported by the literature above. Overall, our results suggest the model is a useful valuation tool. ${ }^{5}$

\footnotetext{
${ }^{5}$ Complementing the results in this article, Lazzati and Menichini (2014b) show that this model also explains numerous important regularities documented by the empirical literature in corporate finance. For instance, it rationalizes the negative association between profitability and leverage, the existence and characteristics of allequity firms, and the inverse relation between dividends and investment-cash flow sensitivities.
} 
The paper is organized as follows. In Section 2, we derive a dynamic version of the DDM in closed-form. In Section 3, we describe the data and the calibration of model parameters. The results from the empirical tests of our model are in Section 4. Section 5 concludes. Appendix 1 contains a sensitivity analysis of the valuation results, while Appendix 2 contains the proofs.

\section{A Dynamic Dividend Discount Model}

In this section, we derive a dynamic version of the standard DDM in closed-form. We solve the problem of the firm (i.e., share price maximization) using discrete-time, infinite-horizon, stochastic dynamic programming within the context of the Adjusted Present Value (APV) method introduced by Myers (1974).

The life horizon of the firm is infinite, which implies that shareholders believe it will run forever. The CEO makes investment and financing decisions at the end of every time period (e.g., quarter, year, etc.) such that the market value of equity is maximized. ${ }^{6}$ (In this paper, we write a tilde on $X$ (i.e., $\tilde{X}$ ) to indicate that the variable is growing over time.) Variable $\widetilde{K}_{t}$ represents the book value of assets in period $t$. The assets of the firm $\widetilde{K}_{t}$ will vary (i.e., increase or decrease) over time, reflecting the investment decisions. In each period, installed capital depreciates at constant rate $\delta>0$. The debt of the firm in period $t, \widetilde{D}_{t}$, matures in one period and is rolled over at the end of every period. ${ }^{7}$ We assume the coupon rate $c_{B}$ equals the market cost of debt $r_{B}$, which implies that book value of debt $\widetilde{D}_{t}$ equals market value of debt $\widetilde{B}_{t}{ }^{8}$ The amount of outstanding debt $\widetilde{B}_{t}$ will increase or decrease over time according to financing decisions. Similar to DeAngelo, DeAngelo, and Whited (2011), we assume debt remains riskfree over the firm's life. This assumption aims to capture the phenomenon of debt conservatism documented by Graham (2000). Lazzati and Menichini (2014b) show that this model generates leverage predictions that are consistent with several key results reported by the capital structure literature. In addition, this feature allows us to obtain an analytic solution for the model.

\footnotetext{
${ }^{6}$ We use the terms market value of equity, share price, and stock price interchangeably in this paper.

${ }^{7}$ Alternatively, $\widetilde{D}_{t}$ could be interpreted as a perpetuity that the firm increases and decreases as needed at the end of every period.

${ }^{8}$ It is straightforward to generalize this component and assume a coupon rate $c_{B}$ different from the market cost of debt $r_{B}$. Without any loss of generality and to simplify notation, we assume they are equal.
} 
We introduce randomness into the model through the profit shock $z_{t}$. It is common in the corporate finance literature to assume that random shocks follow an $\mathrm{AR}(1)$ process in logs

$$
\ln \left(z_{t}\right)=\ln (c)+\rho \ln \left(z_{t-1}\right)+\varepsilon_{t}
$$

where $\rho \in(0,1)$ is the autoregressive parameter that defines the persistence of profit shocks. In other words, a high $\rho$ makes periods of high profit innovations (e.g., economic expansions) and low profit shocks (e.g., recessions) last more on average, and vice versa. The innovation term $\varepsilon_{t}$ is assumed to be an iid normal random variable with mean 0 and variance $\sigma^{2}$. Constant $c>0$ is a drift in logs that scales the moments of the distribution of $z_{t}$. This parameter has a direct impact on expected profits and, thus, regulates the size of the firm. ${ }^{9}$ It is common in the corporate finance literature to normalize $c$ to 1 , which allows for the study of representative firms. Given that our objective is to evaluate the pricing performance of this model with actual firms, we do not do such normalization.

Gross profits in period $t$ are defined by the following function

$$
\widetilde{Y}_{t}=(1+g)^{t(1-\alpha)} z_{t} \widetilde{K}_{t}^{\alpha}
$$

where $z_{t}$ is the profit shock in period $t$ and parameter $\alpha \in(0,1)$ represents the elasticity of capital input. The level of technology in period $t$ takes the form of $(1+g)^{t(1-\alpha)}$, which implies the firm grows at constant rate $g \geq 0$ in each period. With this factor, the firm becomes a scaled up replica of itself over time, and we use this feature in a normalization of growing variables that is required to solve the problem of the firm. Equation (2) says that gross profits also depend on a Cobb-Douglas production function with decreasing returns to scale in capital input. ${ }^{10}$

Every period, the firm pays operating costs $f \widetilde{K}_{t}$ (with $f>0$ ) and corporate earnings are taxed at rate $\tau \in(0,1)$. Therefore, the firm's net profits in period $t$ are

$$
\widetilde{N}_{t}=\left(\widetilde{Y}_{t}-f \widetilde{K}_{t}-\delta \widetilde{K}_{t}-r_{B} \widetilde{B}_{t}\right)(1-\tau)
$$

\footnotetext{
${ }^{9}$ Another way to regulate firm size is to use a constant (e.g., $A$ ) as a factor in equation (2).

${ }^{10}$ Equation (2) can take on only (weakly) positive values. However, the model can be easily extended to allow for negative values of gross profits by subtracting a random variable as a proportion of assets (e.g., $\eta a \widetilde{K}_{t}$ ) in equation (2), where $\eta$ is a Bernoulli random variable and $a$ is a positive constant. While the model still has a closed-form solution, we do not introduce that feature because we do not observe negative profit shocks among the firms in our sample.
} 
Finally, the restriction $(f+\delta)(1-\tau) \leq 1$ guarantees the market value of equity is weakly positive. $^{11}$ With all the previous information, we can state the cash flow that the firm pays to equity-holders in period $t$ as

$$
\widetilde{L}_{t}=\widetilde{N}_{t}-\left[\left(\widetilde{K}_{t+1}-\widetilde{K}_{t}\right)-\left(\widetilde{B}_{t+1}-\widetilde{B}_{t}\right)\right]
$$

Equation (4) implies that the dividend paid to shareholders in period $t$ equals net profits minus the change in equity. We let rate $r_{S}$ represent the market cost of equity and rate $r_{A}$ denote the market cost of capital. For existence of the market value of equity, we impose the usual restriction that the secular growth rate must be lower than the market cost of capital (i.e., $g<r_{A}$ ). Given the current state of the firm at $t=0,\left(\widetilde{K}_{0}, \widetilde{B}_{0}, z_{0}\right)$, the problem of the CEO is to choose an infinite sequence of functions $\left\{\widetilde{K}_{t+1}, \widetilde{B}_{t+1}\right\}_{t=0}^{\infty}$, such that the market value of equity is maximized. We let $E_{0}$ indicate the expectation operator given information at $t=0$ (i.e., $\widetilde{K}_{0}, \widetilde{B}_{0}, z_{0}$ ). The stock price can thereby be expressed as

$$
\widetilde{S}_{0}\left(\widetilde{K}_{0}, \widetilde{B}_{0}, z_{0}\right)=\max _{\left\{\widetilde{K}_{t+1}, \widetilde{B}_{t+1}\right\}_{t=0}^{\infty}} E_{0} \sum_{t=0}^{\infty} \frac{1}{\prod_{j=0}^{t}\left(1+r_{S_{j}}\right)} \widetilde{L}_{t}
$$

subject to the restriction of risk-free debt. Formally, we say debt is risk-free if, in every period, the after-shock book value of equity is weakly positive. In other words, net profits plus the sale of assets, $\widetilde{N}_{t}+\widetilde{K}_{t}$, must be sufficient to cover debt, $\widetilde{B}_{t}$. This condition is equivalent to a weakly positive net-worth covenant. This type of covenant is often used with short-term debt contracts (see, e.g., Leland (1994)), and fits nicely with the one-period debt in our model.

We solve the problem in equation (5) and find the following closed-form for the stock price.

Proposition 1 The market value of equity is

$$
\widetilde{S}_{t}\left(\widetilde{K}_{t}, \widetilde{B}_{t}, z_{t}\right)=\left[(1+g)^{t(1-\alpha)} z_{t} \widetilde{K}_{t}^{\alpha}-f \widetilde{K}_{t}-\delta \widetilde{K}_{t}-r_{B} \widetilde{B}_{t}\right](1-\tau)+\widetilde{K}_{t}-\widetilde{B}_{t}+\widetilde{G}_{t}\left(z_{t}\right)
$$

where the going concern value is $\widetilde{G}_{t}\left(z_{t}\right)=\widetilde{M}_{t}\left(z_{t}\right) P^{*}$. Variable $\widetilde{M}_{t}\left(z_{t}\right)$ is given by

$$
\widetilde{M}_{t}\left(z_{t}\right)=(1+g)^{t} e^{-\frac{1}{2} \sigma^{2} \frac{\alpha}{(1-\alpha)^{2}}} \sum_{n=1}^{\infty}\left(\frac{1+g}{1+r_{A}}\right)^{n} E\left[z_{t+n}^{1 /(1-\alpha)} \mid z_{t}\right]
$$

\footnotetext{
${ }^{11}$ From a practical perspective, if we use the present model letting $(f+\delta)(1-\tau)>1$, the probability of a negative share price is almost zero for standard values of the parameters.
} 
with the general term

$$
E\left[z_{t+n}^{1 /(1-\alpha)} \mid z_{t}\right]=\left(c^{\frac{1-\rho^{n}}{1-\rho}} z_{t}^{\rho^{n}} e^{\frac{1}{2} \sigma^{2} \frac{\left(1-\rho^{2 n}\right)}{\left(1-\rho^{2}\right)} \frac{1}{(1-\alpha)}}\right)^{\frac{1}{1-\alpha}}, \quad n=1,2, \ldots
$$

and variable $P^{*}$ takes the form

$$
P^{*}=\left(W^{*^{\alpha}}-f W^{*}-\delta W^{*}\right)(1-\tau)-r_{A} W^{*}+\left(\frac{1+r_{A}}{1+r_{B}}\right) r_{B} \tau \ell^{*} W^{*}
$$

with

$$
W^{*}=\left(\frac{\alpha}{\frac{r_{A}}{1-\tau}+f+\delta}\right)^{\frac{1}{1-\alpha}} \text { and } \ell^{*}=\frac{1-(f+\delta)(1-\tau)}{1+r_{B}(1-\tau)} .
$$

The proof of Proposition 1 is in Appendix 2. Lazzati and Menichini (2014a) provide a detailed description of each of their components.

The market value of equity is shown in equation (6) and represents an analytic solution of the Gordon Growth Model in the dynamic and stochastic setting. The first three terms in equation (6) represent the after-shock book value of equity, while the last term, $\widetilde{G}_{t}\left(z_{t}\right)$, is the going-concern value. The latter depends on variable $\widetilde{M}_{t}\left(z_{t}\right)$, which captures the effect of the infinite sequence of expected profit shocks, and on variable $P^{*}$, which denotes the dollar return on capital minus the dollar cost of capital at the optimum (plus the interest tax shields). ${ }^{12}$ The going-concern value shows that our model does not require the forecast of future values or the computation of a terminal value. Using only information about the current state (i.e., current book value of equity and gross profits), our model solves systematically for the full sequence of expected future dividends. Furthermore, function $\widetilde{M}_{t}\left(z_{t}\right)$ suggests that our model can become an n-stage dynamic DDM if we substitute the growth rate $g$ on the numerator of the discount factor appropriately. ${ }^{13}$

${ }^{12}$ We obtain $\widetilde{M}_{t}\left(z_{t}\right)$ in the following way. Let $A_{0}=0$ and, for $n=1,2, \ldots$,

$$
A_{n}=A_{n-1}+\left(\frac{1+g}{1+r_{A}}\right)^{n} E\left[z_{t+n}^{1 /(1-\alpha)} \mid z_{t}\right]
$$

Then, we iterate the previous recursion until convergence (i.e., until $A_{n}=A_{n-1}=A$ ). Finally, we compute $\widetilde{M}_{t}\left(z_{t}\right)$ as

$$
\widetilde{M}_{t}\left(z_{t}\right)=(1+g)^{t} e^{-\frac{1}{2} \sigma^{2} \frac{\alpha}{(1-\alpha)^{2}}} A
$$

\footnotetext{
${ }^{13}$ Equation (6) only includes the interest tax shields as financing side effects. The original formulation of APV in
} 
In the next section, we describe our sample and the calibration of model parameters. We subsequently use this information to confirm the empirical validity of our valuation method.

\section{Data and Calibration of Model Parameters}

Our original sample consists of firms in the S\&P 100 Index as of March 2014. We construct this sample using two data sources. Historical accounting data are obtained from the Compustat annual files, while the corresponding stock price data are obtained from the CRSP monthly files. The sample covers the period 1990-2013. For all our empirical analyses, we ensure that accounting data are known at the time the stock price is set in the exchange. Thus, we use the share price observed five months later than the fiscal-year-end of the firm. For instance, we match the accounting data of a December year-end firm with its closing stock price at the end of May of the following year.

We use the data from the previous sample to calibrate parameters $c, \rho, \sigma, \alpha, f, \delta, \tau, r_{B}, r_{A}$, and $g$ for each firm in the $\mathrm{S} \& \mathrm{P} 100$ Index. In order to obtain parameter $f$, we average the ratio Selling, General, and Administrative Expense (XSGA)/Assets - Total (AT) for each firm. We follow the same procedure to get $\delta$ as the ratio of Depreciation and Amortization (DP) over Assets - Total (AT), and $\tau$ as the fraction Income Taxes - Total (TXT)/Pretax Income (PI). Similar to Moyen (2004), we obtain parameters $c, \rho, \sigma$, and $\alpha$ for each company using the firm's autoregressive profit shock process in equation (1) and the gross profits equation (2). The data we use with these equations are Gross Profit (GP) and Assets - Total (AT). We use a risk-free interest rate $\left(r_{f}=r_{B}\right)$ of 0.03 for all firms, which is close to the average 1-year T-Bill yield for the sample period. We follow the procedure described by Kaplan and Ruback (1995) to obtain the market cost of capital. That is, we derive $r_{A}$ using CAPM after unlevering the equity beta and assuming an expected market risk premium of 0.06. Finally, we assume the long-run growth rate $g$ is 0.03 for all firms. ${ }^{14}$

Myers (1974) also allows for other components of the financing side effects, such as the issue costs of new securities, the costs of financial distress, etc.

${ }^{14}$ Computing parameter $g$ for each firm would probably yield better results than those reported in the present study. In addition, using the model as an n-stage dynamic DDM could improve results even more. 
After calibrating model parameters, we check the consistency of their values with the assumptions made by the model in Section 2. We find that some firms have an elasticity of capital $(\alpha)$ above one, while the model constrains that parameter to be between zero and one (i.e., decreasing returns to scale in capital input in the production function in equation (2)). We exclude these firms, which add up to 40. We do not find problems with the other parameters. In addition, we exclude firms with missing data and financial firms (i.e., SIC between 6000 and 6999). After these filters, the final sample includes 1,035 firm-year observations, which implies an average of 45 firms per year.

\section{Empirical Results}

In this section, we study two different aspects of the dynamic model we offer. First, we analyze the consistency between the model estimates and market prices (i.e., how close are the predicted values by our model to the actual market prices on average). Complementing that analysis, we examine how much of the observed variation in contemporaneous share prices is explained by the model estimates. Second, we investigate the possibility to use our model to predict future stock returns and, thus, exploit the differences between those two values.

\subsection{Explanation of Contemporaneous Stock Prices}

We start studying the consistency between model estimates and market prices. To this end, for each firm-year observation in the sample, we construct the market-to-value ratio $(P / V)$, which is the market value of equity $(P)$ divided by the equity value estimated by the dynamic DDM $(V)$. Table I reports the summary statistics for this ratio. Panel A shows that the median of $\mathrm{P} / \mathrm{V}$ is 1.01, which is quite close to the desired value of 1 . This result implies that the median observation of the market value of equity is $1 \%$ larger than the median dynamic DDM estimate. The mean of $\mathrm{P} / \mathrm{V}$ has a value of 1.12 . We believe the difference between the mean and the median is reasonable because the market-to-value ratio is bounded below at zero but unbounded above, which creates a distribution of $P / V$ that is skewed to the right. Panel B in Table I presents different measures of central tendency. For 
instance, it shows that $24.09 \%$ of the estimated values are within $15 \%$ of the market value of equity. Finally, the second column in Table I presents the same statistics using the $\log$ of $P / V$, which could be interpreted as the percentage difference between the market value of equity and the value estimated by the model. These results turn out to be close to those of Kaplan and Ruback (1995), who do a similar analysis to assess the empirical performance of the DCFM in the context of highly leveraged transactions. ${ }^{15}$

[Insert Table I here]

Figure 1 shows the evolution of the mean value of the market-to-value ratio (line with crosses) over the period 1990-2013. In accordance with the results in Table I, the ratio is close to the value of 1 the whole period. As benchmark, we add the mean market-to-book ratio (line with solid squares), which is the market value of equity $(P)$ divided by the book value of equity $(B)$. Both lines attain their maximum values at the end of the 1990s, around the culmination of the stock market surge. It is also clear the impact of the market crash in 2008 on mean $P / V$, shifting it toward 1.

\section{[Insert Figure 1 here]}

We close this subsection analyzing the association between our model estimates and contemporaneous stock prices. That is, we ascertain the proportion of the variation in current prices that is explained by the predictions of the dynamic DDM. Accordingly, we estimate the following basic model

$$
P_{i, t}=\alpha+\beta V_{i, t}+\epsilon_{i, t}
$$

where $P$ denotes the market value of equity and $V$ represents the value estimated by the model. In this specification, $i$ indexes firms, $t$ indexes time periods, and $\epsilon_{i, t}$ is an $i i d$ random term. In

\footnotetext{
${ }^{15}$ Appendix 1 contains a sensitivity analysis of these valuation results with respect to the growth rate and the equity risk premium.
} 
theory, an intercept of zero and a slope of one imply that our model produces unbiased estimates of market values.

The first column in Table II shows the results from this regression. We cannot reject the hypothesis that the intercept is zero $(t=1.16)$. In addition, the slope is very close to one $(\beta=1.02)$ and statistically significant $(t=49.90)$. With an $\mathbf{r}$-squared of $75.8 \%$, the dynamic DDM explains a large proportion of the variation in current stock prices.

[Insert Table II here]

We finally explore the role of the different parts of the dynamic DDM in explaining the variability of contemporaneous stock prices. Proposition 1 shows that the stock price estimated by the model can be separated in the after-shock book value of equity and the going-concern value. Accordingly, we estimate the following model

$$
P_{i, t}=\alpha+\beta_{1} B_{i, t}+\beta_{2} G_{i, t}+\epsilon_{i, t}
$$

where $B$ denotes the after-shock book value of equity in our model (which we equate to the book value of equity in our sample), and $G$ represents the going-concern value in our model, which is given by the last term in equation (6). The results from this regression are in the second column of Table II. The intercept is not significantly different from zero $(t=0.78)$ and both regressors have statistically significant coefficients that are relatively close to one. These results suggest that those model components are important determinants of the stock price. In addition, the r-squared from this regression increases to $77.8 \% .^{16}$

Overall, our valuation results suggest that the dynamic DDM produces equity value estimates that are consistent with market prices and explain a large part of the variation in current stock prices. We next explore the possibility to use the model to exploit the differences between market and estimated values.

\footnotetext{
${ }^{16}$ As benchmark, the third column in Table II displays the results from regressing the market value of equity on the book value of equity. As usual, the intercept is significantly different from zero $(t=11.68)$. In addition, while statistically significant $(t=30.08)$, the slope $(\beta=2.11)$ is far from one. Consistently with previous studies, the r-squared is $53.2 \%$.
} 


\subsection{Forecast of Future Stock Returns}

In the previous subsection, we showed that the dynamic DDM produces value estimates that consistently match current market prices. Although our estimates are very close to contemporaneous share prices on average, we can observe temporary deviations for individual stocks. We then investigate whether it is possible to use the dynamic DDM to predict future stock returns. The underlying idea is to test whether extreme values of the market-to-value ratio $(P / V)$ tend to revert to the mean, which would imply the existence of temporary stock mispricings. If this were true, then the valuation model could be used systematically to take advantage of large deviations from the mean and exploit transitory market inefficiencies.

A common way to test the previous phenomenon is by constructing portfolios based on the ranking of (demeaned) $P / V$ of the firms in the sample. ${ }^{17}$ We then form quintile portfolios where lower quintiles include firms with low $P / V$ and higher quintiles include firms with high $P / V$. Firms in the lower quintile portfolios are, in principle, undervalued and are, therefore, expected to experience higher stock returns in the near future. The opposite is true for firms in the higher quintile portfolios. The last step of the test is to implement the buy-and-hold strategy that involves taking a long position in the bottom quintile portfolio and a short position in the top quintile portfolio. To evaluate this strategy, we form quintile portfolios in May of each year from 1990 through 2009 (i.e., 20 periods) and track the cumulative returns of the strategy over the following 36 months. ${ }^{18}$

Panel A in Table III shows the results of the buy-and-hold strategy. As we explained in the previous paragraph, it consists in constructing portfolios based on the ranking of the market-tovalue ratio. We call them the $P / V$ Portfolios. The three rows display the returns obtained by each portfolio over the 12,24 , and 36 months following the portfolio formation. The lowest $P / V$ quintile firms earn $20.34 \%$ on average over the next 12 months, while the highest $P / V$ quintile firms lose an average of $2.06 \%$ during the same period. As expected, the pattern of returns is strictly monotonic across the quintiles. The sixth column (Q1-Q5) shows the return of

\footnotetext{
${ }^{17}$ We demean $P / V$ of each firm to eliminate the effect of systematic differences between the market and the estimated value of equity.

${ }^{18}$ In order to form those portfolios consistently, we restrict the sample to December year-end firms only, yielding a total of 932 firm-year observations.
} 


\section{the buy-and-hold strategy (i.e., the spread of returns between the lowest and highest} $\mathrm{P} / \mathrm{V}$ portfolios). Over the first 12 months, that difference is $22.40 \%$, and it increases to $49.09 \%$ after 36 months of portfolio formation. The seventh column shows that the strategy returns are statistically significant. The last column shows the percentage of periods in which the strategy earned positive returns. Specifically, it shows that in $95 \%$ of the periods (i.e., 19 out of 20 years), the strategy produced positive returns after 36 months of portfolio formation.

To show the significance of our findings, Panel B of Table III shows the results for the same strategy using the book value of equity instead of the equity value estimated by the model. In this case, the portfolios are formed based on the ranking of the market-to-book ratio and we call them the $P / B$ Portfolios. The buy-and-hold strategy using $P / V$ considerably outperforms the $P / B$ strategy in each of the three investment horizons. For example, over the period of 36 months, the former yields roughly $20 \%$ more than the latter (49.09\% versus $29.10 \%)$ on average. Furthermore, the returns of the $P / B$ strategy are not monotonic across the quintiles. Finally, the $t$-statistics and the percentage of winner periods are, in general, lower than those of the strategy with the market-to-value ratio. ${ }^{19}$ A key difference between $P / V$ and $P / B$ is that the equity value estimated by the model $(V)$ makes a prediction of the whole future sequence of firm dividends based on the fundamental characteristics of the firm (e.g., the curvature of the production function, the volatility of profits, etc.), which is not true for book equity $(B)$. We believe that difference underlies the superior performance of $P / V$ over $P / B$.

\section{[Insert Table III here]}

Figure 2 displays the evolution of the average returns of the $P / V$ and $P / B$ portfolios over the 36 months after portfolio formation. Both strategies obtain positive returns on average during

\footnotetext{
${ }^{19}$ As benchmark, Panel C of Table III shows the results of a third buy-and-hold strategy. This strategy consists simply in mixing the previous two in equal parts (i.e., $50 \%$ of the $P / V$ Portfolios and $50 \%$ of the P/B Portfolios) and we call them the Hybrid Portfolios. While the returns of this strategy are naturally the midpoints of the other two, the benefits stem from the diversification effect. The hybrid portfolios have lower risk than the other two, which appears indirectly as higher $t$-statistics and a larger percentage of winner periods. For instance, after 36 months, this strategy obtained positive returns $100 \%$ of the times (i.e., 20 out of 20 years).
} 
the entire period, with the $P / V$ portfolios (line with crosses) outperforming the $P / B$ portfolios (line with solid squares). Overlaying the two lines are fitted curves that display the general trends. The concavity or flattening of the latter could be interpreted as the result of $P / V$ and $P / B$ reverting to their mean values, which would imply that there are no more potential benefits from keeping the portfolios much longer (i.e., the potential gains have already been realized). This concavity also suggests that, if transaction costs are not too high, it would be convenient to renew the portfolios as soon as the new financial statements become public (e.g., quarterly or annually).

[Insert Figure 2 here]

In summary, the dynamic DDM is a good predictor of long-term stock returns. Because the portfolios are constructed based on information that is known at the time of portfolio formation, the buy-and-hold strategies described above are actually tradable.

\section{Conclusion}

We derive a dynamic version of the dividend discount model (DDM) in closed-form and evaluate its empirical performance. The implementation of our method relies on widely available financial data and implies a new valuation approach that involves two simple steps. First, model parameters (i.e., the proxies for the economic fundamentals of the firm) must be calibrated or estimated. Second, the model uses current data on book value of equity and gross profits to determine the stock price. It does so by systematically projecting the infinite sequence of future expected dividends. Thus, our model does not require to actually forecast any future value (including a terminal value), helping to reduce the degree of discretion on the user side.

The empirical evaluation of the dynamic DDM yields promising results. First, we find that our model forecasts stock prices consistently, that is, model estimates are very close to market prices on average. Second, the model explains a large proportion (around 75\%) of the observed variability in current stock prices. Finally, we find that the model can be used to predict future stock returns in the cross-section of firms by exploiting temporary differences between market 
prices and model estimates. For instance, constructing portfolios based on the ratio of the market value of equity to the equity value estimated by the model, we find that simple buy-and-hold strategies earn considerable positive returns over the three following years (e.g., an average of around $22 \%, 37 \%$, and $49 \%$ returns after 1, 2, and 3 years, respectively, of portfolio formation). 


\section{References}

[1] Bernard, Victor L., 1995, The Feltham-Ohlson framework: implications for empiricists, Contemporary Accounting Research 11, 733-747.

[2] Copeland, Thomas E., John F. Weston, and Kuldeep Shastri, 2005, Financial theory and corporate policy, Pearson Addison Wesley.

[3] DeAngelo, Harry, Linda DeAngelo, and Toni M. Whited, 2011, Capital structure dynamics and transitory debt, Journal of Financial Economics 99, 235-261.

[4] Dixit, Avinash K., and Robert S. Pindyck, 1994, Investment under uncertainty, Princeton University Press.

[5] Edwards, Edgar O., and Philip W. Bell, 1961, The theory and measurement of business income, University of California Press, Berkeley, CA.

[6] Frankel, Richard, and Charles M. C. Lee, 1998, Accounting valuation, market expectation, and cross-sectional stock returns, Journal of Accounting and Economics 25, 283-319.

[7] Graham, John R., 2000, How big are the tax benefits of debt?, Journal of Finance 55, 1901-1941.

[8] Jorgenson, Dale W. and Kevin J. Stiroh, 2000, U.S. economic growth at the industry level, American Economic Review 90, 161-167.

[9] Kaplan, Steven N., and Richard S. Ruback, 1995, The valuation of cash flow forecasts: an empirical analysis, Journal of Finance 50, 1059-1093.

[10] Koller, Tim, Marc Goedhart, and David Wessels, 2010, Valuation. Measuring and managing the value of companies, John Wiley \& Sons.

[11] Lazzati, Natalia, and Amilcar A. Menichini, 2014a, A dynamic approach to the dividend discount model, Review of Pacific Basin Financial Markets and Policies, Forthcoming.

[12] Lazzati, Natalia, and Amilcar A. Menichini, 2014b, A dynamic model of the firm: structural explanations of key empirical findings, Mimeo. 
[13] Leland, Hayne E., 1994, Corporate debt value, bond covenants, and optimal capital structure, Journal of Finance 49, 1213-1252.

[14] Moyen, Nathalie, 2004, Investment-cash flow sensitivities: Constrained versus unconstrained firms, Journal of Finance 59, 2061-2092.

[15] Myers, Stewart C., 1974, Interactions of corporate financing and investment decisionsimplications for capital budgeting, Journal of Finance 29, 1-25.

[16] Ohlson, James A., 1991, The theory of value and earnings, and an introduction to the BallBrown analysis, Contemporary Accounting Research 7, 1-19.

[17] Ohlson, James A., 1995, Earnings, book values, and dividends in security valuation, Contemporary Accounting Research 11, 661-687.

[18] Preinreich, Gabriel A. D., 1938, Annual survey of economic theory: the theory of depreciation, Econometrica 6, 219-241.

[19] Strebulaev, Ilya A., and Toni M. Whited, 2012, Dynamic models and structural estimation in corporate finance, Foundations and Trends in Finance 6, 1-163.

[20] Williams, John B., 1938, The theory of investment value, Harvard University Press. 


\section{Appendix 1: Sensitivity Analysis}

In this appendix, we discuss the valuation results in the context of a sensitivity analysis with respect to the equity risk premium and the growth rate. These are the only two parameters for which we choose specific values for all firms.

Panel A in Table IV shows the results for the base case with a growth rate of 0.03 and an equity risk premium of 0.06 . Panel B suggests that reducing the equity risk premium to 0.04 makes the median value of $P / V$ decrease to 0.64 , while increasing the former to 0.08 makes the latter go up to 1.36. The last column shows that the median absolute error increases when we change the equity risk premium from the base case in any direction (i.e., up or down). That is, the median absolute error becomes a minimum close to the value of 0.06 for the equity risk premium.

Panel $\mathrm{C}$ in Table IV displays the effects of varying the growth rate. A reduction in the growth rate increases the median market-to-value ratio monotonically, and vice versa. As with the equity risk premium, changing the base case growth rate in any direction increases the median absolute error. Overall, these results suggest that our choice of the base case values for these parameters is reasonable.

[Insert Table IV here] 


\section{Appendix 2: Proofs}

The proof of Proposition 1 requires an intermediate result that we present next.

Lemma 2 Restricting debt to be risk-free, the maximum level of book leverage in each period is given by

$$
\ell^{*}=\frac{1-(f+\delta)(1-\tau)}{1+r_{B}(1-\tau)}
$$

Proof We say debt is risk-free if, in every period, the following inequality is true for all $z^{\prime}$

$$
\left(z^{\prime} K^{\prime \alpha}-f K^{\prime}-\delta K^{\prime}-r_{B} \ell K^{\prime}\right)(1-\tau)+K^{\prime}-\ell K^{\prime} \geq 0
$$

That is, risk-free debt implies that next-period, after-shock book value of equity must be weakly positive for all $z^{\prime}{ }^{20}$ In other words, net profits, $\left(z^{\prime} K^{\prime^{\alpha}}-f K^{\prime}-\delta K^{\prime}-r_{B} \ell K^{\prime}\right)(1-\tau)$, plus the sale of assets, $K^{\prime}$, must be sufficient to cover debt, $\ell K^{\prime}$.

Given that the worst-case scenario is $z^{\prime}=0$, the maximum book leverage ratio consistent with risk-free debt, $\ell^{*}$, satisfies

$$
\left(-f K^{\prime}-\delta K^{\prime}-r_{B} \ell^{*} K^{\prime}\right)(1-\tau)+K^{\prime}-\ell^{*} K^{\prime}=0 .
$$

Working on the previous expression, we can derive the maximum level of book leverage as

$$
\ell^{*}=\frac{1-(f+\delta)(1-\tau)}{1+r_{B}(1-\tau)}
$$

which completes the proof. ${ }^{21}$

\section{Proof of Proposition 1}

The maximization in equation (5) requires a normalization of growing variables that keeps the expectation of the payoff function in the future periods bounded. This normalization is equivalent to the one used to find the solution of the canonical Gordon Growth Model. Let vector $\widetilde{X}_{t}=$ $\left\{\widetilde{K}_{t}, \widetilde{B}_{t}, \widetilde{Y}_{t}, \widetilde{N}_{t}, \widetilde{L}_{t}, \widetilde{S}_{t}\right\}$ contain the growing variables of the model. We then transform vector $\widetilde{X}_{t}$

\footnotetext{
${ }^{20}$ The same result is true if we define risk-free debt using the market value of equity as opposed to the book value of equity. That is, in both cases we arrive at equation (13) as the maximum level of book leverage consistent with risk-free debt. In order to simplify notation, we use the book value of equity.

${ }^{21}$ The restriction $(f+\delta)(1-\tau) \leq 1$ described in Section 2 also guarantees that $\ell^{*} \geq 0$.
} 
in the following way: $X_{t}=\widetilde{X}_{t} /(1+g)^{t}$. Using the normalized variables and modifying the payoff function accordingly, the market value of equity can be expressed as

$$
S_{0}\left(K_{0}, B_{0}, z_{0}\right)=\max _{\left\{K_{t+1}, B_{t+1}\right\}_{t=0}^{\infty}} E_{0} \sum_{t=0}^{\infty} \frac{(1+g)^{t}}{\prod_{j=0}^{t}\left(1+r_{S_{j}}\right)} L_{t}
$$

subject to keeping debt risk-free. Because we use the Adjusted Present Value method of firm valuation, we solve the problem of the firm in equation (17) in three steps. First, we determine the value of the unlevered firm, $S_{u_{0}}\left(K_{0}, z_{0}\right)$. Second, we solve for optimal debt and compute the present value of the financing side effects. Finally, we obtain the value of the levered firm in equation (17).

The market value of equity for the unlevered firm can be expressed as

$$
S_{u_{0}}\left(K_{0}, z_{0}\right)=\max _{\left\{K_{t+1}\right\}_{t=0}^{\infty}} E_{0} \sum_{t=0}^{\infty}\left(\frac{1+g}{1+r_{A}}\right)^{t} L_{u_{t}}
$$

where $L_{u_{t}}=N_{u_{t}}-\left(K_{t+1}-K_{t}\right)$ and $N_{u_{t}}=\left(Y_{t}-f K_{t}-\delta K_{t}\right)(1-\tau)$. We let normalized variables with primes indicate values in the next period and normalized variables with no primes denote current values. Then, the Bellman equation for the problem of the firm in equation (18) is given by

$$
S_{u}(K, z)=\max _{K^{\prime}}\left\{\left(z K^{\alpha}-f K-\delta K\right)(1-\tau)-(1+g) K^{\prime}+K+\frac{(1+g)}{\left(1+r_{A}\right)} E\left[S_{u}\left(K^{\prime}, z^{\prime}\right) \mid z\right]\right\} .
$$

We use the guess and verify method as the proof strategy. Thus, we start by guessing that the solution is given by

$$
S_{u}(K, z)=\left(z K^{\alpha}-f K-\delta K\right)(1-\tau)+K+M(z) P_{u}^{*}
$$

where

$$
\begin{gathered}
M(z)=e^{-\frac{1}{2} \sigma^{2} \frac{\alpha}{(1-\alpha)^{2}}} \sum_{n=1}^{\infty}\left\{( \frac { 1 + g } { 1 + r _ { A } } ) ^ { n } \left(c^{\frac{1-\rho^{n}}{1-\rho}} z^{\rho^{n}} e^{\left.\left.\frac{1}{2} \sigma^{2} \frac{\left(1-\rho^{2 n}\right)}{\left(1-\rho^{2}\right)} \frac{1}{(1-\alpha)}\right)^{\frac{1}{1-\alpha}}\right\}}\right.\right. \\
P_{u}^{*}=\left(W^{*^{\alpha}}-f W^{*}-\delta W^{*}\right)(1-\tau)-r_{A} W^{*} \\
W^{*}=\left(\frac{\alpha}{\frac{r_{A}}{1-\tau}+f+\delta}\right)^{\frac{1}{1-\alpha}} .
\end{gathered}
$$

We obtained this initial guess as the solution of equation (19) by the backward induction method. 
We now verify our guess. To this end, let us write

$$
S_{u}(K, z)=\max _{K^{\prime}}\left\{F\left(K^{\prime}, K, z\right)\right\}
$$

with $F$ defined as the objective function in equation (19).

The FOC for this problem is

$$
\partial F\left(K^{\prime}, K, z\right) / \partial K^{\prime}=-(1+g)+\frac{(1+g)}{\left(1+r_{A}\right)}\left[\left(E\left[z^{\prime} \mid z\right] \alpha K^{* \alpha-1}-f-\delta\right)(1-\tau)+1\right]=0
$$

and optimal capital turns out to be

$$
K^{*}=E\left[z^{\prime} \mid z\right]^{\frac{1}{1-\alpha}} W^{*}
$$

where $W^{*}$ is as in equation (23).

Finally, the market value of equity for the unlevered firm becomes

$$
\begin{aligned}
& S_{u}(K, z)=\left(z K^{\alpha}-f K-\delta K\right)(1-\tau)-(1+g) K^{*}+K+ \\
& \frac{(1+g)}{\left(1+r_{A}\right)}\left[\left(E\left[z^{\prime} \mid z\right] K^{* \alpha}-f K^{*}-\delta K^{*}\right)(1-\tau)+K^{*}+\right. \\
& \left.E\left[M\left(z^{\prime}\right) \mid z\right] P_{u}^{*}\right] \\
& =\left(z K^{\alpha}-f K-\delta K\right)(1-\tau)+K-(1+g) E\left[z^{\prime} \mid z\right]^{\frac{1}{1-\alpha}} W^{*}+ \\
& \frac{(1+g)}{\left(1+r_{A}\right)}\left\{E\left[z^{\prime} \mid z\right]^{\frac{1}{1-\alpha}}\left[\left(W^{*^{\alpha}}-f W^{*}-\delta W^{*}\right)(1-\tau)+W^{*}\right]+\right. \\
& \left.E\left[M\left(z^{\prime}\right) \mid z\right] P_{u}^{*}\right\} \\
& =\left(z K^{\alpha}-f K-\delta K\right)(1-\tau)+K+ \\
& \frac{(1+g)}{\left(1+r_{A}\right)}\left(e^{-\frac{1}{2} \sigma^{2} \frac{\alpha}{(1-\alpha)^{2}}} E\left[z^{\prime \frac{1}{1-\alpha}} \mid z\right]+E\left[M\left(z^{\prime}\right) \mid z\right]\right) P_{u}^{*} \\
& =\left(z K^{\alpha}-f K-\delta K\right)(1-\tau)+K+M(z) P_{u}^{*}
\end{aligned}
$$

which is equivalent to our initial guess in equation (20).

Next, we obtain optimal debt. In each period, the firm solves the following problem

$$
B^{*}=\max _{B^{\prime}}\left\{B^{\prime}-\frac{1}{\left(1+r_{B}\right)} B^{\prime}\left[1+r_{B}(1-\tau)\right]\right\}
$$

subject to the restriction of risk-free debt. Because $\tau>0$, the firm increases debt as much as possible (as long as it remains risk-free) in order to maximize the tax benefits of debt. Then, optimal debt is $B^{*}=\ell^{*} K^{*}$ where

$$
\ell^{*}=\frac{1-(f+\delta)(1-\tau)}{1+r_{B}(1-\tau)}
$$


as shown in Lemma 2. The present value of the financing side effects turns out to be

$$
\begin{aligned}
Q(z) & =\left(\frac{1+g}{1+r_{A}}\right)\left\{\left(\frac{1+r_{A}}{1+r_{B}}\right) r_{B} \tau B^{*}+E\left[Q\left(z^{\prime}\right) \mid z\right]\right\} \\
& =M(z)\left(\frac{1+r_{A}}{1+r_{B}}\right) r_{B} \tau \ell^{*} W^{*}
\end{aligned}
$$

where $M(z)$ is as in equation (21). Under this financial policy, the amount of debt and interest payments will vary with the future asset cash flows (i.e., they depend on future firm performance). Then, because future interest tax shields will have a level of risk in line with that of the firm cash flows, we use the cost of capital, $r_{A}$, as the discount rate.

The third step consists in obtaining the market value of equity for the levered firm. If we assume the firm used debt $B$ in the previous period, and now has to pay interest $r_{B} B(1-\tau)$, then the stock price for the levered firm is

$$
\begin{aligned}
S(K, B, z) & =S_{u}(K, z)+M(z)\left(\frac{1+r_{A}}{1+r_{B}}\right) r_{B} \tau \ell^{*} W^{*}-B-r_{B} B(1-\tau) \\
& =\left(z K^{\alpha}-f K-\delta K-r_{B} B\right)(1-\tau)+K-B+G(z)
\end{aligned}
$$

where $G(z)=M(z) P^{*}$ and variable $P^{*}$ takes the form

$$
P^{*}=\left(W^{*^{\alpha}}-f W^{*}-\delta W^{*}\right)(1-\tau)-r_{A} W^{*}+\left(\frac{1+r_{A}}{1+r_{B}}\right) r_{B} \tau \ell^{*} W^{*} .
$$

The last part of the proof consists in transforming normalized variables back into growing variables. For this step, we return to the initial notation with growing variables, where nextperiod assets are $\widetilde{K}_{t+1}$ and current-period assets are $\widetilde{K}_{t}$. Then, the required transformation is: $\tilde{X}_{t}=(1+g)^{t} X_{t}$, where vector $X_{t}=\left\{K_{t}, B_{t}, Y_{t}, N_{t}, L_{t}, S_{t}\right\}$ contains the normalized variables of the model. Finally, the optimal decisions of the firm with growing variables are given by

$$
\widetilde{K}_{t+1}^{*}\left(z_{t}\right)=(1+g)^{t+1} E\left[z_{t+1} \mid z_{t}\right]^{\frac{1}{1-\alpha}} W^{*} \text { and } \widetilde{B}_{t+1}^{*}\left(z_{t}\right)=\ell^{*} \widetilde{K}_{t+1}^{*}\left(z_{t}\right)
$$

and the growing market value of equity is

$$
\widetilde{S}_{t}\left(\widetilde{K}_{t}, \widetilde{B}_{t}, z_{t}\right)=\left[(1+g)^{t(1-\alpha)} z_{t} \widetilde{K}_{t}^{\alpha}-f \widetilde{K}_{t}-\delta \widetilde{K}_{t}-r_{B} \widetilde{B}_{t}\right](1-\tau)+\widetilde{K}_{t}-\widetilde{B}_{t}+\widetilde{G}_{t}\left(z_{t}\right)
$$

as shown in Proposition 1. 


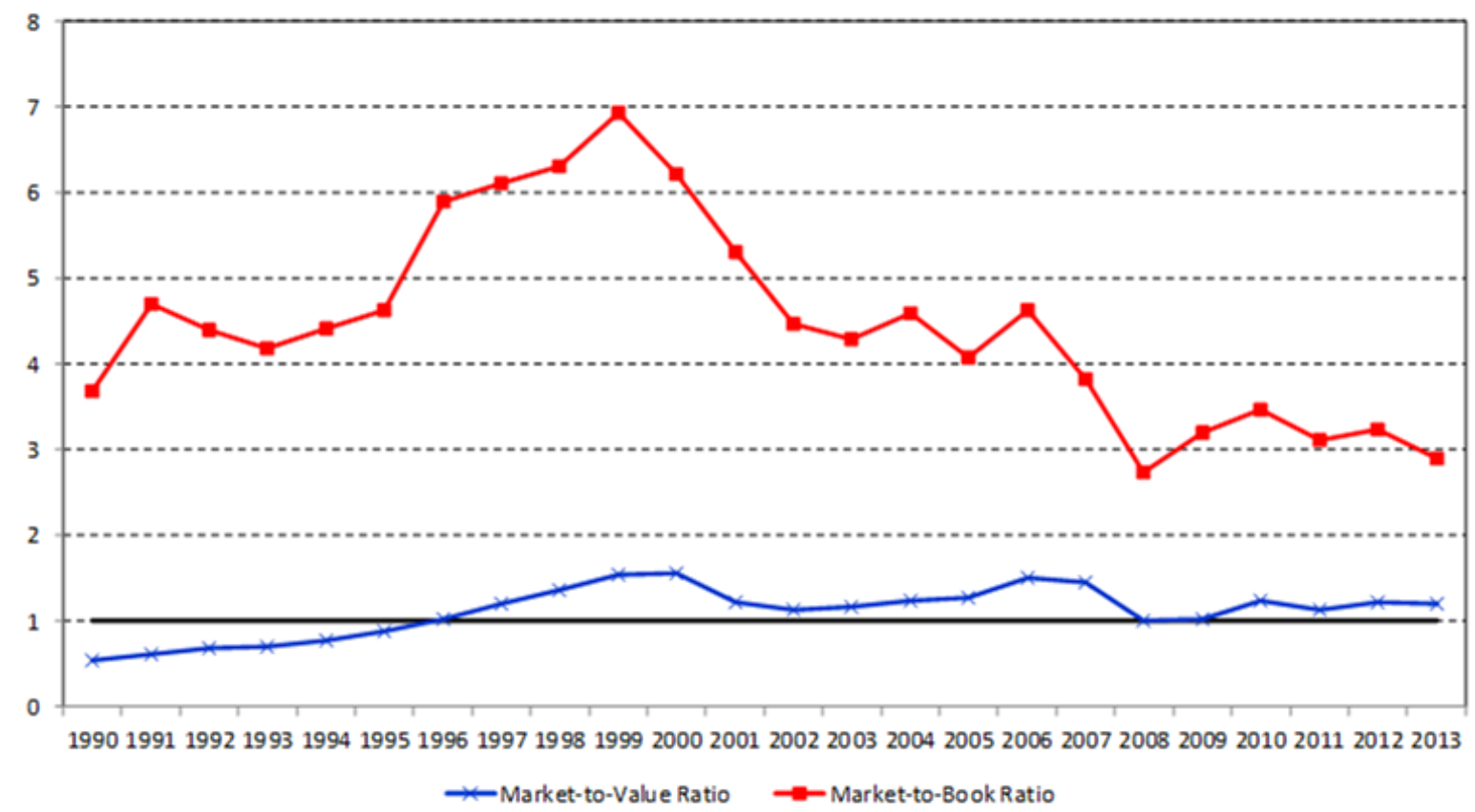

Figure 1. Evolution of the market-to-value ratio. The figure displays the evolution over time of the mean market-to-value ratio (line with crosses) and the mean market-to-book ratio (line with solid squares) for a sample of firms included in the S\&P 100 Index as of March 2014. The sample covers the period 1990-2013. The market-to-value ratio is the market value of equity divided by the value estimated by the model. The market-to-book ratio is the market value of equity divided by the book value of equity. 


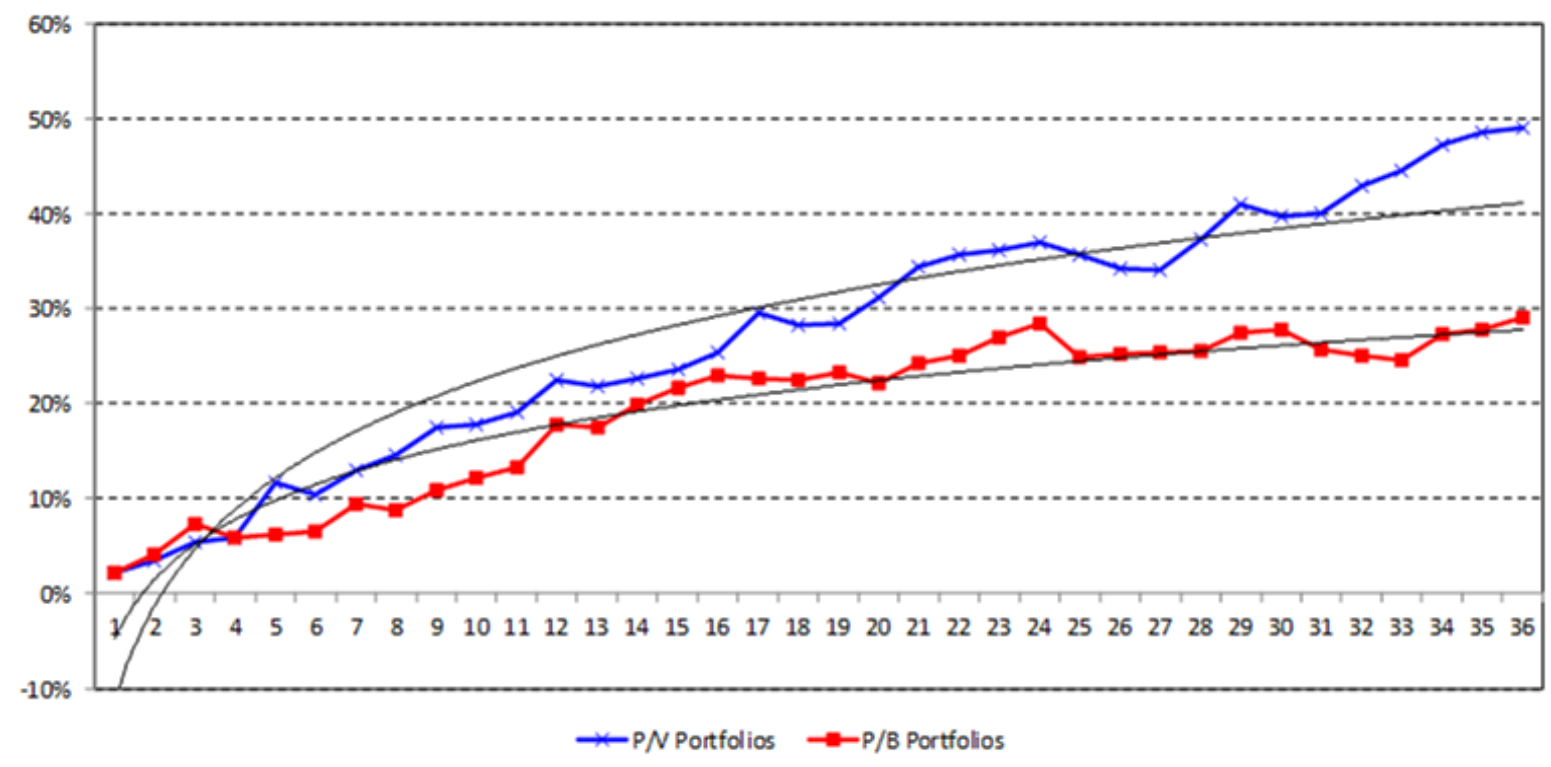

Figure 2. Cumulative buy-and-hold returns. The figure displays the cumulative returns of the buy-and-hold strategies for the $P / V$ and $P / B$ portfolios during the 36 months following portfolio formation. These portfolios are constructed with a sample of firms included in the S\&P 100 Index as of March 2014. The sample covers the period 1990-2013. $P / V$ is the market-to-value ratio (i.e., the market value of equity divided by the equity value estimated by the model). $P / B$ is the market-to-book ratio (i.e., the market value of equity divided by the book value of equity). Portfolios are formed by sorting firms into quintiles according to their $P / V$ and $P / B$ ratios at the end of May of each year. The buy-and-hold strategy consists in buying firms in the bottom quintile and selling firms in the top quintile. 


\section{Table I}

\section{Valuation Results}

The table shows the valuation results of the dynamic DDM for a sample of firms included in the S\&P 100 Index as of March 2014. The sample covers the period 1990-2013. P/V is the market-to-value ratio (i.e., the market value of equity divided by the equity value estimated by the model). The $\log (P / V)$ results derive from computing the log of the market-to-value ratio. The first line in Panel B shows the percentage of times that the value estimated by the model is within $15 \%$ of the market value of equity. The second line in Panel B shows the median value of the absolute difference between the equity value estimated by the model and the market value of equity (in percent). The third line in Panel B shows the median value of the squared difference between the value estimated by the model and the market value of equity (in percent). $t$-statistics are in parentheses.

\begin{tabular}{|c|c|c|}
\hline & $P / V$ & $\log (P / V)$ \\
\hline \multicolumn{3}{|c|}{ Panel A: Summary Statistics } \\
\hline \multirow[t]{2}{*}{ Mean } & 1.12 & $-3.41 \%$ \\
\hline & $(45.85)$ & $(-3.20)$ \\
\hline Median & 1.01 & $0.22 \%$ \\
\hline Standard Deviation & 0.56 & $25.37 \%$ \\
\hline Interquartile Range & 0.68 & $30.04 \%$ \\
\hline \multicolumn{3}{|c|}{ Panel B: Performance Measures } \\
\hline Percentage within $15 \%$ & $24.09 \%$ & $49.44 \%$ \\
\hline Median Absolute Error & $33.15 \%$ & $15.25 \%$ \\
\hline Median Squared Error & $11.46 \%$ & $2.32 \%$ \\
\hline
\end{tabular}


Table II

Regression of the Market Value of Equity

The table shows the results from different cross-sectional regressions of the market value of equity. In column (1), the regressor is the equity value estimated by the model. In column (2), the regressors are the book value of equity and the going-concern value estimated by the model. In column (3), the regressor is the book value of equity. The sample is composed of firms included in the S\&P 100 Index as of March 2014, and covers the period 1990-2013. $t$-statistics are in parentheses.

\begin{tabular}{|c|c|c|c|}
\hline Variable & (1) & (2) & (3) \\
\hline \multirow[t]{2}{*}{ Intercept } & 1574.30 & 1018.43 & 19307.16 \\
\hline & $(1.16)$ & $(0.78)$ & $(11.68)$ \\
\hline \multirow[t]{2}{*}{ Equity Value Estimate } & 1.02 & & \\
\hline & $(49.90)$ & & \\
\hline \multirow[t]{2}{*}{ Book Value of Equity } & & 1.44 & 2.11 \\
\hline & & $(27.11)$ & $(30.08)$ \\
\hline \multirow[t]{2}{*}{ Going-Concern Value Estimate } & & 0.84 & \\
\hline & & $(29.69)$ & \\
\hline$R^{2}$ & 0.758 & 0.778 & 0.532 \\
\hline
\end{tabular}




\section{Table III}

\section{Cumulative Buy-and-Hold Returns of Quintile Portfolios}

The table presents the cumulative buy-and-hold returns of three different strategies. $P / V$ Portfolios is the strategy that constructs portfolios based on the ranking of the market-to-value ratio $(P / V)$. $P / B$ Portfolios is the strategy that constructs portfolios based on the ranking of the market-to-book ratio $(P / B)$. Hybrid Portfolios is the strategy that constructs portfolios based on mixing the previous two in equal parts (i.e., $50 \%$ of the $P / V$ Portfolios and $50 \%$ of the $P / B$ Portfolios). Ret12, Ret24, and Ret36 are the average 12-month, 24-month, and 36-month buy-and-hold returns of each strategy, respectively. Q1-Q5 is the average spread of returns between the lowest $(Q 1)$ and highest (Q5) quintile portfolios. \% Winners is the percentage of periods (out of 20) in which the strategy yielded positive returns.

\begin{tabular}{|c|c|c|c|c|c|c|c|c|}
\hline & $Q 1$ & $Q 2$ & $Q 3$ & $Q 4$ & $Q 5$ & $Q 1-Q 5$ & $t$-statistic & $\%$ Winners \\
\hline \multicolumn{9}{|c|}{ Panel A: P/V Portfolios } \\
\hline Ret 12 & $20.34 \%$ & $7.33 \%$ & $1.72 \%$ & $0.07 \%$ & $-2.06 \%$ & $22.40 \%$ & 4.48 & $90.00 \%$ \\
\hline $\operatorname{Ret} 24$ & $31.60 \%$ & $16.23 \%$ & $4.06 \%$ & $0.25 \%$ & $-5.35 \%$ & $36.95 \%$ & 5.79 & $90.00 \%$ \\
\hline $\operatorname{Ret} 36$ & $42.13 \%$ & $17.77 \%$ & $10.09 \%$ & $0.19 \%$ & $-6.96 \%$ & $49.09 \%$ & 5.42 & $95.00 \%$ \\
\hline \multicolumn{9}{|c|}{ Panel B: P/B Portfolios } \\
\hline Ret 12 & $14.30 \%$ & $8.13 \%$ & $4.97 \%$ & $4.73 \%$ & $-3.50 \%$ & $17.80 \%$ & 3.54 & $75.00 \%$ \\
\hline $\operatorname{Ret} 24$ & $22.75 \%$ & $15.37 \%$ & $6.56 \%$ & $9.83 \%$ & $-5.63 \%$ & $28.38 \%$ & 4.58 & $90.00 \%$ \\
\hline $\operatorname{Ret} 36$ & $27.72 \%$ & $24.88 \%$ & $9.19 \%$ & $6.36 \%$ & $-1.37 \%$ & $29.10 \%$ & 4.36 & $80.00 \%$ \\
\hline \multicolumn{9}{|c|}{ Panel C: Hybrid Portfolios } \\
\hline Ret 12 & $17.32 \%$ & $7.73 \%$ & $3.35 \%$ & $2.40 \%$ & $-2.78 \%$ & $20.10 \%$ & 4.88 & $95.00 \%$ \\
\hline $\operatorname{Ret} 24$ & $27.18 \%$ & $15.80 \%$ & $5.31 \%$ & $5.04 \%$ & $-5.49 \%$ & $32.66 \%$ & 6.43 & $95.00 \%$ \\
\hline $\operatorname{Ret} 36$ & $34.93 \%$ & $21.32 \%$ & $9.64 \%$ & $3.28 \%$ & $-4.17 \%$ & $39.09 \%$ & 6.64 & $100.00 \%$ \\
\hline
\end{tabular}




\section{Table IV}

\section{Sensitivity Analysis}

The table shows the sensitivity analysis of the market-to-value ratio for a sample of firms included in the S\&P 100 Index as of March 2014. The sample covers the period 1990-2013. $P / V$ is the market-to-value ratio (i.e., the market value of equity divided by the equity value estimated by the model). The median absolute error is the median value of the absolute difference between the equity value estimated by the model and the market value of equity (in percent).

\begin{tabular}{cccc}
\hline $\begin{array}{c}\text { Growth } \\
\text { Rate }\end{array}$ & $\begin{array}{c}\text { Equity } \\
\text { Risk } \\
\text { Premium }\end{array}$ & Median P/V & $\begin{array}{c}\text { Median } \\
\text { Absolute } \\
\text { Error }\end{array}$ \\
\hline \multicolumn{4}{c}{ Panel A: Base Case } \\
\hline $3 \%$ & $6 \%$ & 1.01 & $33.15 \%$ \\
\hline \multicolumn{4}{c}{ Panel B: Change in Equity Risk Premium } \\
\hline $3 \%$ & $4 \%$ & 0.64 & $62.05 \%$ \\
$3 \%$ & $5 \%$ & 0.83 & $41.39 \%$ \\
$3 \%$ & $7 \%$ & 1.18 & $33.60 \%$ \\
$3 \%$ & $8 \%$ & 1.36 & $35.51 \%$ \\
\hline \multicolumn{4}{c}{ Panel C: Change in Growth Rate } \\
\hline $1 \%$ & $6 \%$ & 1.44 & $39.31 \%$ \\
$2 \%$ & $6 \%$ & 1.23 & $34.17 \%$ \\
$4 \%$ & $6 \%$ & 0.75 & $45.33 \%$ \\
$5 \%$ & $6 \%$ & 0.52 & $93.76 \%$ \\
\hline
\end{tabular}

